Pesq. Vet. Bras. 31(3):199-205, março 2011

\title{
Transferência de imunidade passiva em cordeiros de corte manejados extensivamente em clima tropical ${ }^{1}$
}

\author{
Carolina Faria Turquino², Karina Keller M.C. Flaiban ${ }^{3}$ \\ e Júlio Augusto Naylor Lisbôa ${ }^{*}$
}

\begin{abstract}
Turquino C.F., Flaiban K.K.M.C \& Lisbôa J.A.N. 2011. [Passive transfer of immunity in meat lambs reared in the tropics on extensive management.] Transferência de imunidade passiva em cordeiros de corte manejados extensivamente sob condição de clima tropical. Pesquisa Veterinária Brasileira 31(3):199-205. Departamento de Clínicas Veterinárias, Centro de Ciências Agrárias, Universidade Estadual de Londrina, Campus Universitário, Cx. Postal 6001, Londrina, PR 86051-990, Brazil. E-mail: janlisboa@uel.br

Aspects related to passive transfer of immunity (PTI) were studied in 290 newborn lambs, crosses of Texel, kept with their mothers on extensive management intropical weather. Blood samples were taken between 24 and 36 hours of life. Serum gamma glutamyltransferase activity, total protein concentration, measured by refractometry and colorimetry, albumin, alfa, beta and gammaglobulins concentrations, measured by agarose gel electrophoresis, and IgG concentration estimated by the zinc sulphate turbidity test were determined. The lambs were grouped according to sex, ewe number of parturitions and body condition scoring, number of lambs born, birth weight and vitality. The risk factors for failure of passive transfer of immunity (FPT) were identified and the association with lamb mortality was tested. Correlations between variables were established. There was no effect of sex, number of parturitions of ewes and ewe body condition scoring on PTI of lambs. However there were differences between singles and twins and between lambs born with good or lightweight $(<3$ $\mathrm{kg})$. The FPT was infrequent (12.4\%), more likely in twins $(\mathrm{p}=0.026)$ and in lightweight lambs $(p<0.001)$, and was strongly associated with lamb deaths up to 60 days of age $(p<0.001)$. The global mortality rate was $11.3 \%$; and $30.5 \%$ of the lambs with FPT died, almost all in their first month of life. The total protein concentration, measured by refractometry, was correlated $(p<0.001)$ with gammaglobulins $(r=0.816)$ and $\operatorname{lgG}(r=0.810)$; and values $\leq 5.0 \mathrm{~g} / \mathrm{dL}$ can be accepted for the diagnosis of FPT. Under tropical weather conditions FTP must be considered infrequent in crossbred meat lambs. However the surveillance and care must be intensified with twins and lambs with low birth weight.
\end{abstract}

INDEX TERMS: Immunoglobulins, IgG, serum proteins, mortality, sheep, newborn.

RESUMO.- Aspectos relacionados à transferência de imunidade passiva (TIP) foram estudados em 290 cordeiros recém-nascidos, cruzas Texel, manejados extensivamente

\footnotetext{
${ }^{1}$ Recebido em 5 de maio de 2010.

Aceito para publicação em 21 de setembro de 2010.

Dissertação de Mestrado do primeiro autor.

2 Mestre em Ciência Animal, Universidade Estadual de Londrina (UEL). Endereço particular: Rua Espírito Santo 1114, apto 1402, Londrina, PR 86020-420, Brasil.

${ }^{3}$ Departamento de Medicina Veterinária Preventiva, Centro de Ciências Agrárias (CCA), UEL, Londrina, PR.

${ }^{4}$ Departamento de Clínicas Veterinárias, CCA, UEL, Campus Universitário, Cx. Postal 6001, Londrina, PR 86051-990l. * Autor para correspondência: janlisboa@uel.br
}

em contato permanente com as suas mães, e criados em clima tropical. Amostras de sangue foram colhidas dos cordeiros uma única vez entre 24 e 36 horas de vida para obtenção do soro sanguíneo. Foram determinadas a atividade da gama glutamiltransferase e as concentrações de proteínas totais por refratometria e colorimetria, de albumina, alfa, beta e gamaglobulinas por eletroforese e de IgG estimada pela turvação pelo sulfato de zinco. Os cordeiros foram agrupados de acordo com o sexo, o número de partos das oveIhas, o escore de condição corporal (ECC) da ovelha, o número de cordeiros nascidos, o peso e a vitalidade ao nascimento. Os fatores de risco para a ocorrência de falha na transferência de imunidade passiva (FTIP) foram identificados e a sua associação com a mortalidade de cordeiros foi 
testada. Foram estabelecidas correlações entre as variáveis estudadas. A TIP não foi influenciada pelo sexo, pelo número de partos ou pelo ECC das ovelhas. Houve diferenças entre os cordeiros únicos e gêmeos e entre os que nasceram com peso $\geq 3 \mathrm{~kg} \mathrm{e}<3 \mathrm{~kg}$. A FTIP foi pouco frequente $(12,4 \%)$, mais provável em gêmeos $(p=0,026)$ e em cordeiros leves $(p<0,001)$ e esteve fortemente associada com a mortalidade dos cordeiros até os 60 dias de vida $(p<0,001)$. A taxa de mortalidade geral foi de $11,3 \%$; e $30,5 \%$ dos cordeiros com FTIP morreram, quase todos no primeiro mês de vida. A concentração de proteína total determinada por refratometria se correlacionou $(p<0,001)$ com as concentrações de gamaglobulinas $(r=0,816)$ e de $\lg G(r=0,810)$ e o valor crítico $\leq 5,0 \mathrm{~g} / \mathrm{dL}$ para a proteína total pode ser admitido como indicador de FTIP. Sob condições de clima tropical a FTIP pode ser considerada pouco frequente em cordeiros mestiços de corte, entretanto, a vigilância e os cuidados devem ser intensificados no caso do nascimento de cordeiros gêmeos com peso reduzido.

TERMOS DE INDEXAÇÃO: Imunoglobulinas, IgG, proteínas séricas, mortalidade, ovinos, neonatos.

\section{INTRODUÇÃO}

Além dos processos fisiológicos de adaptação à vida extra-uterina, a transferência de imunidade passiva (TIP) é um evento importante para a saúde do recém-nascido das espécies ruminantes. Os bezerros, cabritos e cordeiros nascem com concentrações muito baixas de gamaglobulinas e os seus sistemas imunológicos ainda não possuem capacidade plena de resposta. A absorção das imunoglobulinas, especialmente da classe G (lgG), presentes no colostro da mãe garante a proteção no período inicial da vida (Tizard 2002). Diferentes fatores ligados à mãe, ao neonato e ao manejo podem provocar falha na transferência de imunidade passiva (FTIP) (Halliday 1978, Radostits et al. 1994) e o reconhecimento desses fatores de risco tem grande importância prática porque pode direcionar a adoção de medidas que evitem ou reduzam a ocorrência dessa condição.

Existe grande número de informações sobre o assunto na espécie bovina. Porém, os trabalhos realizados com os ovinos são menos numerosos e resultam de investigações realizadas, na sua maioria, em países de clima temperado ou frio, e em ovinos de diferentes raças com aptidão variada para a produção de lã, de carne ou aptidão mista. Esses estudos apontaram que o sucesso da TIP pode ser comprometido no caso das ovelhas primíparas e das mais velhas (Halliday 1976, Gilbert et al. 1988), dos partos gemelares (Halliday 1976, Hunter et al. 1977, McGuire et al. 1983, Christley et al. 2003), da restrição alimentar das ovelhas durante a gestação (Halliday 1978, Mellor \& Murray 1985, 1986) e do nascimento de cordeiros prematuros (Hough et al. 1990) e de cordeiros com peso reduzido (Ahmad et al. 2000, Christley et al. 2003, Kahn et al. 2006). Contudo, as contradições entre os resultados não são incomuns (AISabbagh et al. 1995, Hashemi et al. 2008, Swanson et al. 2008).
Além disso, as variações entre as raças podem ser marcantes (Gilbert et al. 1988). É incerto que esses conhecimentos possam ser corretamente aplicados aos rebanhos manejados em condições de clima tropical.

A literatura brasileira sobre o assunto é recente e pouco numerosa (Nunes 2006, Flaiban et al. 2007, 2009, Silva et al. 2007, 2009, Campos et al. 2009). Concentra-se, sobretudo, em raças com aptidão para a produção de carne, o que é natural em virtude do grande incremento atual da ovinocultura de corte no país. Nunes (2006) realizou o único estudo mais abrangente sobre a TIP, apresentando algumas de suas causas em ovinos Santa Inês, criados em Minas Gerais. O presente trabalho foi desenvolvido com a finalidade de investigar um número maior de fatores capazes de influenciar a TIP em cordeiros mestiços de corte manejados extensivamente, sob condições naturais, em clima tropical, e de correlacionar a ocorrência da FTIP com a mortalidade de cordeiros nos primeiros dois meses de vida.

\section{MATERIAL E MÉTODOS}

O projeto foi aprovado pelo Comitê de Ética e Experimentação Animal da Universidade Estadual de Londrina, registrado sob o número de protocolo CEEA/UEL 09/08. Foram acompanhados os nascimentos de 290 cordeiros durante as estações de parição nos anos de 2007 e 2008, compreendendo o período entre os meses de julho e setembro, em uma propriedade rural localizada no município de Eldorado, estado do Mato Grosso do Sul. As coordenadas da propriedade são Latitude 234' 49,67"S e Longitude 54¹1'22,88"O, com 337 m de altitude. O clima caracteriza-se, de forma geral, como tropical com estação seca e temperatura amena no inverno; tendo apresentado temperatura média anual de 22,9 e $22,4^{\circ} \mathrm{C}$ e umidade relativa do ar média anual de 65 e 66, nos anos de 2007 e de 2008, respectivamente. A precipitação pluviométrica anual variou de 1.294,3mm em 2007 a 1.471,3mm em 2008, sendo sempre menor nos meses de junho a setembro.

Os ovinos eram criados com a finalidade de produção de carne em sistema de manejo extensivo. As matrizes eram frutos de cruzamentos entre três raças com aptidão para a produção de carne: lle de France, Suffolk e Texel. Todas as ovelhas foram cobertas por carneiros Texel. Ao longo de toda a gestação as ovelhas eram manejadas extensivamente durante o dia em pastos de capim Tanzânia (Panicum maximum) e Brachiaria brizantha. À noite eram alojadas em piquetes de grama Estrela Africana (Cynodon plectostachyus). Suplemento mineral comercial ${ }^{5}$ era oferecido permanentemente em cocho coberto. O mesmo padrão de manejo foi mantido nos dois anos em que se desenvolveu o estudo, mantendo-se a lotação de pastagem de aproximadamente 12 ovelhas por hectare, baixa

\footnotetext{
5 Ovinofós $\circledast$, Tortuga Conpanhia Zootécnica Agrária, Av. Brigadeiro Faria Lima 2066, Jardim Paulistano São Paulo, SP.

${ }^{6}$ Cydectin injetável ${ }$, Fort Dodge Saúde Animal Ltda, Rua Luiz Fernando Rodrigues 1701, Vila Boa

7 Ripercol L injetável囚, Fort Dodge Saúde Animal Ltda, Rua Luiz Fernando Rodrigues 1701, Vila Boa Vista, Campinas, SP.

8 Sintoxan Polivalente $\circledast$, Merial Saúde Animal Ltda, Av. Carlos Grimaldi 1610, São Quirino, Campinas, SP.

${ }^{9}$ Kevac®, Hipra Saúde Animal Ltda, Avenida do Lami 6133, Belém Novo, Porto Alegre, RS.
} 
o suficiente para evitar a condição de escassez de forragem. $\mathrm{Na}$ segunda metade da gestação as ovelhas foram vermifugadas uma única vez com moxidectina ${ }^{6}$ na dose de $0,2 \mathrm{mg} / \mathrm{kg}$ ou com levamizol ${ }^{7}$ na dose de $5,5 \mathrm{mg} / \mathrm{kg}$ e vacinadas contra clostridioses ${ }^{8}$ e contra ceratoconjuntivite ${ }^{9}$.

Próximo ao parto as ovelhas eram agrupadas em um piquete maternidade durante o dia, onde permaneciam sob vigilância mais intensa, e mantidas presas em uma instalação durante à noite, onde recebiam feno de aveia. A permanência nesse manejo variava de uma a duas semanas até que ocorresse o parto. Os partos aconteciam de maneira natural e sem a interferência do homem, exceto nas situações raras de distocia. A ovelha e seu(s) cordeiro(s) permaneciam no piquete maternidade por aproximadamente 12 horas após o parto. Posteriormente eram alojados junto ao lote de recém-paridas em outro piquete e permaneciam durante a primeira semana, livres durante o dia e presos durante a noite, com suplementação de feno de aveia. Os cordeiros eram mantidos em contato permanente com as suas mães e a ingestão do colostro era natural e espontânea. Nas primeiras 12 horas de vida, os cordeiros eram numerados para identificação e o umbigo era desinfetado com solução de iodo $5 \%$ uma única vez.

No dia do parto a ovelha era identificada e examinada registrando-se as informações em fichas individuais contendo o(s) número(s) do(s) seu(s) cordeiro(s). Foram registrados a idade da ovelha e o número de partos, levantados do banco de dados da propriedade. O escore de condição corporal (ECC) da ovelha foi avaliado seguindo os critérios apresentados por Rankins et al. (2005) com classificação em uma escala de 1 a 5. O comportamento da ovelha foi avaliado subjetivamente classificando-se como alerta e apática, dócil ou não dócil. A interação entre a ovelha e sua prole foi avaliada subjetivamente de acordo com o interesse que a ovelha demonstrava e com os cuidados que dispensava ao(s) recém-nascido(s) após o parto, classificando-se como boa habilidade materna, pouco interesse ou rejeição. O tipo de parto foi classificado como eutocia ou distocia. A glândula mamária foi examinada por inspeção e por palpação para identificação da presença de processos agudos ou crônicos de mamite, uni ou bilaterais.

Os registros individuais dos cordeiros contemplavam a informação sobre a data e hora do nascimento, o sexo e o tamanho da prole (únicos, gêmeos e trigêmeos). Os cordeiros foram pesados, e foram medidas a altura da cernelha, o comprimento da coluna vertebral (entre o atlas e a primeira vértebra coccígea) e o perímetro torácico, posicionando a fita métrica imediatamente caudal ao cotovelo. O vigor ou a vitalidade do cordeiro foi avaliado conforme critérios subjetivos de acordo com o padrão de comportamento e de atividade motora apresentado pelo neonato próximo ao nascimento e às 24 horas de vida. Foi classificado como ativo, alerta ou com boa vitalidade o cordeiro que conseguiu se levantar, caminhar e mamar pela primeira vez com sucesso dentro da primeira hora de vida e que se manteve ativo 24 horas após. Foram considerados letárgicos os cordeiros que executaram essas primeiras tarefas com mais lentidão e se apresentavam apáticos às 24 horas de vida. Ao longo dos primeiros dois meses de vida os cordeiros foram acompanhados registrando-se a ocorrência e data da morte.

Amostras de sangue foram colhidas de todos os cordeiros, por venopunção da jugular externa, entre 24 e 36 horas de vida, utilizando frascos a vácuo de $5 \mathrm{~mL}$ sem anticoagulante e agulhas $25 \times 8 \mathrm{~mm}$. O soro foi obtido por centrifugação após a retração do coágulo e foi conservado por congelação a $20^{\circ} \mathrm{C}$ negativos até o momento das análises laboratoriais. As determinações laboratoriais compreenderam: a concentração de proteína total sérica por refratometria e pelo método do biureto utilizando reagente comercial $^{10}$; e a atividade da gama glutamiltransferase pelo método cinético segundo a técnica modificada de Szasz et al. (1969), empregando reagente comerci$\mathrm{al}^{11}$. As leituras espectrofotométricas foram realizadas no espectrofotômetro semi-automático ${ }^{12}$. As concentrações séricas das frações protéicas albumina, alfa, beta e gamaglobulinas foram determinadas por eletroforese (Kremers et al. 1967). Empregou-se gel de agarose ${ }^{13}$, tampão Tris de $\mathrm{pH}$ 9,5 e corrida eletroforética por 20 min em corrente de $100 \mathrm{~V}^{14}$.

A concentração sérica de imunoglobulinas $G$ foi estimada pela técnica de turvação pelo sulfato de zinco com leitura espectrofotométrica, conforme o método empregado por Pfeiffer et al. (1977) com modificações. Adicionou-se $0,1 \mathrm{~mL}$ de soro a $6 \mathrm{~mL}$ de uma solução contendo $208 \mathrm{mg}$ de $\mathrm{ZnSO}_{4} \cdot 7 \mathrm{H}_{2} \mathrm{O}$ por litro de água destilada. Após uma hora de repouso, a absorbância da mistura foi mensurada por espectrofotometria ${ }^{15}$ em comprimento de onda de 620nm. Devido à instabilidade da solução, foram realizadas três leituras e considerada a média final. A quantidade de IgG foi estimada com o uso de uma curva padrão previamente traçada com concentrações conhecidas de IgG ovina ${ }^{16}$, a saber: zero (água destilada), 125, 400 e 1.000mg/ dL. As amostras foram inicialmente diluídas na proporção 1:2 e quando o resultado superava o valor estimado de $1.000 \mathrm{mg} /$ $\mathrm{dL}$, foram processadas novamente após diluição na proporção de 1:5.

A concentração sérica de $1.500 \mathrm{mg} / \mathrm{dL}$ de IgG foi arbitrariamente considerada como o limite crítico abaixo do qual se caracterizou o insucesso da TIP. Para o estudo da relação entre a FTIP e os fatores de risco foram consideradas as distribuições de frequência.

Para as comparações estatísticas, os cordeiros foram distribuídos por grupos de acordo com o sexo, o ECC da mãe, o número de parições da mãe, o tamanho da prole (únicos, gêmeos e trigêmeos), o peso ao nascimento ( $<3 \mathrm{~kg}$ considerado baixo e $\geq 3 \mathrm{~kg}$ considerado adequado), a vitalidade exibida ao nascimento e ao longo do primeiro dia de vida, e a mortalidade ou não até os 60 dias de idade. O teste t foi empregado para contraste entre médias de machos e fêmeas, de peso adequado e baixo peso, de boa vitalidade e letárgicos e de sobreviventes e não sobreviventes. A análise de variância foi utilizada para comparações relacionadas ao $\mathrm{ECC}$, ao número de par-

\footnotetext{
10 Proteínas Totais PP®, Gold Analisa Diagnóstica Ltda, Avenida Nossa Senhora de Fátima 2363, Carlos Prates, Belo Horizonte, MG.

11 Gama GT®, Gold Analisa Diagnóstica Ltda, Avenida Nossa Senhora de Fátima 2363, Carlos Prates, Belo Horizonte, MG.

12 Chemistry Analyser CA-2005, B4B Diagnostic Division, Biomarchesini Produtos Científicos, Estrada dos Açores 1051, Santo Antonio de Lisboa, Florianópolis, SC.

${ }^{13}$ Celmgel de Agarose Geral ${ }^{\circledR}$, Companhia Equipadora de Laboratórios Modernos (CELM), Alameda Amazonas 764, Alphaville, Barueri,

14 Sistema para Eletroforese SE-250®, Companhia Equipadora de Laboratórios Modernos (CELM), Alameda Amazonas 764, Alphaville, Barueri, SP.

15 Espectrofotômetro E 225-D®, Companhia Equipadora de Laboratórios Modernos (CELM), Alameda Amazonas 764, Alphaville, Barueri, SP.

${ }^{16}$ Sheep IgG Vet-Rid Plate, Bethyl Laboratories, Inc., West FM 1097, Montgomery, TX, USA.
} SP. 
tos das ovelhas e ao número de cordeiros nascidos. A associação entre a ocorrência de FTIP e o peso do cordeiro, o número de fetos, o comportamento do cordeiro e a mortalidade foi testada aplicando-se o teste de Qui-Quadrado. Foram estabelecidos os coeficientes de correlação entre as variáveis estudadas, empregando-se o teste de Pearson. Para todos os testes admitiu-se uma probabilidade de erro de $5 \%$ (Curi 1998).

\section{RESULTADOS E DISCUSSÃO}

Os valores do conjunto das variáveis estudadas estão apresentados no Quadro 1, e separados de acordo com o sexo do cordeiro. Esses valores podem ser admitidos como valores de referência para cordeiros recém-nascidos saudáveis e caracterizam a TIP bem sucedida. São coerentes com os relatados por outros autores (Keay \& Doxey 1984, Silva et al. 2007, 2009, Campos et al. 2009). Ao contrário destes, entretanto, não foi possível observar uma separação nítida das betaglobulinas em frações beta 1 e beta 2. Segundo Kaneko (1997) nem sempre a separação é possível em ruminantes.

Os machos foram mais pesados do que as fêmeas e apresentaram concentração de gamaglobulinas e atividade da GGT um pouco menores. Essas diferenças não são biologicamente relevantes e não caracterizam diferenças no processo de TIP entre os sexos. De fato, a concentração de IgG não foi diferente entre machos e fêmeas, o que está de acordo com outras observações (Ciupercescu 1977, Hunter et al. 1977, Sawyer et al. 1977, Gilbert et al. 1988,
Quadro 1. Comparação das variáveis do proteinograma sérico e de biometria entre cordeiros mestiços de corte com 24 horas de vida, agrupados de acordo com o sexo

\begin{tabular}{|c|c|c|}
\hline & $\operatorname{Machos}(n=149)$ & Fêmeas(n=141) \\
\hline $\begin{array}{l}\text { Proteína total por } \\
\text { refratometria }(\mathrm{g} / \mathrm{dL})\end{array}$ & $6,899^{a} \pm 1,138$ & $7,123^{a} \pm 1,138$ \\
\hline $\begin{array}{l}\text { Proteína total por } \\
\text { colorimetria }(\mathrm{g} / \mathrm{dL})\end{array}$ & $7,025^{a_{ \pm}}, 670$ & $7,307^{a_{ \pm}}+515$ \\
\hline Albumina (g/dL) & $3,276^{a} \pm 0,669$ & $3,261^{a} \pm 0,610$ \\
\hline Alfaglobulina (g/dL) & $0,248^{a} \pm 0,164$ & $0,233^{a} \pm 0,168$ \\
\hline Betaglobulina (g/dL) & $0,686^{a} \pm 0,175$ & $0,683^{a} \pm 0,165$ \\
\hline Gamaglobulina (g/dL) & $2,809^{b} \pm 1,508$ & $3,126^{a_{ \pm}}, 344$ \\
\hline Globulinas (g/dL) & $3,743^{a} \pm 1,533$ & $4,042^{a} \pm 1,393$ \\
\hline Albumina:Globulinas & $1,141^{a} \pm 0,821$ & $0,982^{a} \pm 0,668$ \\
\hline GGT (UI/L) & $1542,07^{b} \pm 1133,39$ & $1935,64^{a_{ \pm}}+1210,21$ \\
\hline $\lg G(g / d L)$ & $2,973^{a_{ \pm}}, 309$ & $3,208^{a_{1}}+1,034$ \\
\hline Peso (kg) & $4,160^{a_{ \pm}}+0,991$ & $3,848^{b} \pm 0,950$ \\
\hline $\begin{array}{l}\text { Comprimento da } \\
\text { coluna vertebral }(\mathrm{cm})\end{array}$ & $42,389^{a} \pm 3,448$ & $41,766^{a} \pm 3,527$ \\
\hline Perímetro torácico $(\mathrm{cm})$ & $37,074^{a} \pm 3,300$ & $36,262^{\mathrm{b}} \pm 3,441$ \\
\hline Altura da cernelha $(\mathrm{cm})$ & $41,913^{a} \pm 3,158$ & $40,943^{\mathrm{b}} \pm 3,047$ \\
\hline
\end{tabular}

Bekele et al. 1992, Ahmad et al. 2000, Kahn et al. 2006, Nunes 2006).

Pode-se observar no Quadro 2 que a TIP não foi influenciada pelo estado nutricional das ovelhas. Mesmo os cordeiros filhos das ovelhas com ECC 1, indicativo de desequilíbrio franco, alcançaram sucesso na TIP. Isso pode ser explicado pelo fato de ovelhas que sofrem restrição nutricional durante a gestação acabarem produzindo volu-

Quadro 2. Efeito de fatores relacionados à ovelha ou ao cordeiro sobre as concentrações de proteína total por refratometria (PT), de gamaglobulinas (Gama) e de imunoglobulina $\mathrm{G}$ (IgG) e sobre a atividade da gama glutamiltransferase (GGT) no soro sanguíneo de cordeiros mestiços de corte com 24 horas de vida

\begin{tabular}{|c|c|c|c|c|c|}
\hline Fator & $\mathrm{n}$ & PT (g/dL) & Gama(g/dL) & $\operatorname{lgG}(g / d L)$ & GGT(U/L) \\
\hline \multicolumn{6}{|l|}{ ECC da ovelha } \\
\hline 1 & 24 & $6,575^{a} \pm 1,271$ & $2,526^{a} \pm 1,462$ & $2,496^{a} \pm 1,140$ & $1167,9^{a} \pm 1174,4$ \\
\hline 2 & 139 & $6,963^{a} \pm 1,216$ & $2,981^{a} \pm 1,460$ & $3,092^{a} \pm 1,234$ & $1764,9^{a_{ \pm}} 1169,8$ \\
\hline 3 & 111 & $7,115^{a_{ \pm 1}, 139}$ & $2,990^{a} \pm 1,351$ & $3,192^{a} \pm 1,134$ & $1797,2^{a_{ \pm}} 1202,4$ \\
\hline 4 & 16 & $7,313^{a} \pm 1,200$ & $3,405^{a} \pm 1,741$ & $3,205^{a} \pm 1,030$ & $1865,2^{a} \pm 1101,9$ \\
\hline \multicolumn{6}{|c|}{ № de partos da ovelha } \\
\hline 1 & 87 & $7,014^{a_{1}}+1,299$ & $2,948^{a b} \pm 1,529$ & $3,068^{a_{ \pm}}, 327$ & $1750,6^{a b} \pm 1189,0$ \\
\hline 2 & 65 & $7,265^{a} \pm 0,951$ & $3,332^{\mathrm{ab}} \pm 1,187$ & $3,375^{a} \pm 0,785$ & $1885,1^{\mathrm{a}} \pm 1024,8$ \\
\hline 3 & 42 & $6,733^{a} \pm 1,057$ & $2,538^{a b} \pm 1,178$ & $3,057^{a} a_{ \pm 1,183}$ & $1738,6^{a b} \pm 1426,0$ \\
\hline 4 & 43 & $6,977^{a} \pm 1,345$ & $2,904^{a b} \pm 1,564$ & $3,088^{a} \pm 1,212$ & $1637,8^{a b} \pm 1032,7$ \\
\hline 5 & 29 & $7,200^{a} \pm 1,184$ & $3,379^{a} \pm 1,537$ & $3,053^{a} \pm 1,190$ & $2041,4^{a} \pm 1450,0$ \\
\hline 6 a 8 & 24 & $6,600^{a} \pm 1,255$ & $2,370^{\mathrm{b}} \pm 1,467$ & $2,471^{a} \pm 1,371$ & $1050,5^{b} \pm 799,0$ \\
\hline \multicolumn{6}{|l|}{ № de cordeiros } \\
\hline únicos & 151 & $7,313^{a} \pm 1,112$ & $3,161^{a_{ \pm}}, 300$ & $3,318^{a} \pm 1,113$ & $1782,3^{a} \pm 1213,1$ \\
\hline gêmeos & 127 & $6,665^{\mathrm{b}} \pm 1,164$ & $2,711^{b} \pm 1,504$ & $2,820^{b} \pm 1,204$ & $1616,0^{a} \pm 1096,4$ \\
\hline trigêmeos & 12 & $6,817^{a b} \pm 1,574$ & $3,148^{a b} \pm 1,986$ & $3,011^{a b} \pm 1,405$ & $2360,3^{a} \pm 1576,4$ \\
\hline \multicolumn{6}{|l|}{ Peso do cordeiro } \\
\hline$\geq 3 \mathrm{~kg}$ & 256 & $7,068^{a} \pm 1,161$ & $3,037^{a} \pm 1,365$ & $3,168^{a} \pm 1,114$ & $1764,2^{a_{ \pm}} 1185,2$ \\
\hline$<3 \mathrm{~kg}$ & 34 & $6,559^{b} \pm 1,365$ & $2,407^{b} \pm 1,823$ & $2,478^{b} \pm 1,522$ & $1501,2^{a_{ \pm}} \pm 1181,6$ \\
\hline \multicolumn{6}{|l|}{ Vigor do cordeiro } \\
\hline boa vitalidade & 275 & $7,040^{a} \pm 1,184$ & $2,990^{a} \pm 1,431$ & $3,112^{a} \pm 1,175$ & $1750,3^{a} \pm 1188,5$ \\
\hline letárgico & 15 & $6,427^{a} \pm 1,287$ & $2,471^{a_{ \pm} 1,495}$ & $2,631^{a_{ \pm}}, 352$ & $1423,3^{a_{ \pm}} 1127,8$ \\
\hline \multicolumn{6}{|l|}{ Mortalidade } \\
\hline sobreviventes & 262 & $7,095^{a} \pm 1,116$ & $3,052^{a} \pm 1,386$ & $3,165^{a} \pm 1,107$ & $1768,2^{a} \pm 1161,8$ \\
\hline morte até 60 dias & 28 & $6,193^{b} \pm 1,579$ & $2,137^{b} \pm 1,654$ & $2,358^{b} \pm 1,618$ & $1408,1_{ \pm} a_{ \pm 1371,9}$ \\
\hline
\end{tabular}


me menor de colostro (Mellor \& Murray 1985, 1986). Porém a sua concentração de IgG não se reduz (Al-Sabbagh et al. 1995, Nunes 2006, Hashemi et al. 2008, Swanson et al. 2008). O menor volume de colostro pode ser suficiente para permitir a TIP bem sucedida no cordeiro único, entretanto, aumenta o risco de FTIP no caso dos gêmeos. Dentre os 24 cordeiros nascidos de ovelhas que pariram muito magras (com ECC 1), 14 eram gêmeos, metade desses exibia letargia ao nascimento e quatro apresentavam peso reduzido $(<3 \mathrm{~kg})$. A FTIP foi observada em somente um desses cordeiros gêmeos.

Segundo Rankins et al. (2005), o ECC considerado ideal para a ovelha ao parto varia entre 2,5 e 3 . Nesse trabalho não se utilizou casa decimal para classificação do ECC. A maioria das ovelhas estudadas pariu com ECC 2, o que, conforme o critério mencionado, indica um possível desequilíbrio nutricional leve em pelo menos parte das ovelhas. Sessenta e seis cordeiros nascidos dessas ovelhas eram gêmeos e seis eram trigêmeos. Dezoito desses cordeiros nasceram com peso inferior a $3 \mathrm{~kg}$, mas somente seis apresentaram insucesso na TIP. Isso reforça o conceito de que nem sempre existe uma relação evidente entre o estado nutricional da ovelha e a TIP nos seus cordeiros (Halliday 1978, Christley et al. 2003, Flaiban et al. 2007, 2009).

Igualmente a relatos anteriores (Gilbert et al. 1988, Ahmad et al. 2000, Kahn et al. 2006, Nunes 2006), as concentrações de IgG no soro dos cordeiros no segundo dia de vida não foi influenciada pela idade da ovelha, representada pelo número de partos (Quadro 2). Segundo Halliday (1978) a TIP poderia ser comprometida em cordeiros filhos de primíparas e de ovelhas acima de sete anos de idade porque produzem volume menor de colostro. Entretanto, a concentração de IgG no colostro não é menor nas primíparas (Halliday 1976, Nunes 2006) e somente se reduz nas ovelhas com mais do que sete anos (Gilbert et al. 1988). O número de partos da ovelha, como um fator isolado, parece não ter importância sobre o sucesso ou insucesso da TIP.

A probabilidade de FTIP e de mortalidade é maior nos cordeiros gêmeos (McGuire et al. 1983, Christley et al. 2003, Nunes 2006). Gilbert et al. (1988) demonstraram que a concentração de IgG diminuiu linearmente com o aumento do número de cordeiros nascidos da mesma mãe o que indica que a competição natural entre os gêmeos, e mais acirrada entre os trigêmeos, pode ser um fator importante para a ocorrência de FTIP. Essa observação não foi confirmada no presente estudo. Os cordeiros nascidos únicos apresentaram concentrações de PT, de gamaglobulinas e de $\lg G$, de fato, maiores do que os gêmeos. No entanto, não diferentes das dos trigêmeos (Quadro 2). Devese ressaltar que o número de trigêmeos nesse estudo foi muito pequeno. Apesar das diferenças, os valores médios observados caracterizam a TIP bem sucedida nos três grupos. Isso prova que, mesmo no caso mais especial dos trigêmeos, o número de fetos pode não interferir com o sucesso da TIP. Diferenças entre gêmeos e únicos nem sempre foram observadas por outros autores (Halliday
1976, Ciupercescu 1977, Hunter et al. 1977, Sawyer et al. 1977, Bekele et al. 1992). Provavelmente o número de fetos pode não provocar efeito sobre a TIP isoladamente. Contudo, o sucesso da TIP poderá ser comprometido se os cordeiros de gestações com fetos múltiplos nascerem com peso reduzido e letárgicos.

Os cordeiros únicos foram em média mais pesados $(4,66 \pm 0,69 \mathrm{~kg})$ do que os gêmeos $(3,72 \pm 0,54 \mathrm{~kg})$ e os trigêmeos $(3,40 \pm 0,45 \mathrm{~kg})$, e tiveram maior comprimento da coluna vertebral, maior perímetro torácico e maior altura da cernelha, o que está de acordo com Christley et al. (2003). Poucos cordeiros que exibiram boa vitalidade ao nascimento nasceram com peso abaixo de $3 \mathrm{~kg}(\mathrm{n}=23)$, variando entre 2 e 2,8 $\mathrm{kg}$. Quinze deles eram gêmeos e três eram trigêmeos, nascidos de mães que pariram com ECC 2 ou 3. Somente um desses cordeiros nasceu de uma ovelha muito magra (ECC 1). Embora o baixo peso seja considerado um fator de risco para a FTIP (Ahmad et al. 2000, Christley et al. 2003, Kahn et al. 2006), a diferença dos valores de PT, de gamaglobulina e de IgG entre cordeiros com peso adequado $(\geq 3 \mathrm{~kg})$ e com baixo peso $(<3 \mathrm{~kg}$ ) não caracterizou FTIP (Quadro 2). Deve-se salientar que, apesar de mais leves, a maioria desses cordeiros era ativa, exibindo bom vigor ao nascimento e ao longo do primeiro dia de vida.

Dos 15 cordeiros que exibiram letargia, oito nasceram com peso inferior a $3 \mathrm{~kg}, 12$ eram gêmeos e sete eram filhos de ovelhas que pariram muito magras (ECC 1). Ou seja, esses cordeiros reuniam mais do que um fator geralmente considerado como de risco para a FTIP (Halliday 1978, Radostits et al. 1994, Christley et al. 2003). Apesar disso, as concentrações de PT, de gamaglobulinas e de IgG e a atividade da GGT, ainda que numericamente inferiores, não foram significativamente diferentes das dos cordeiros não letárgicos (Quadro 2). O contrário foi verificado quando se agruparam os cordeiros de acordo com a sobrevivência ou não até 60 dias de vida.

Não existe um valor crítico da concentração sérica de IgG universalmente aceito para caracterizar a condição de FTIP em cordeiros. Valores tão baixos quanto $500 \mathrm{mg} / \mathrm{dL}$ (Vihan 1988) ou $600 \mathrm{mg} / \mathrm{dL}$ (McGuire et al. 1983) e tão altos quanto $1.000 \mathrm{mg} / \mathrm{dL}$ (Gilbert et al. 1988, Hough et al. 1990), $1.100 \mathrm{mg} / \mathrm{dL}$ (Waelchli et al. 1994) e $1.500 \mathrm{mg} / \mathrm{dL}$ (Hunter et al. 1977) já foram arbitrariamente apontados. Nesse trabalho decidiu-se adotar o valor de $1.500 \mathrm{mg} / \mathrm{dL}$ de IgG como crítico, abaixo do qual se considerou que a TIP não foi bem sucedida.

A FTIP ocorreu em poucos cordeiros $(n=36)$ com uma frequência de $12,4 \%$. Essa taxa é menor do que as obtidas por Hunter et al. (1977), que utilizaram o mesmo valor crítico de IgG adotado nesse trabalho, e por outros autores brasileiros (Flaiban et al. 2007, 2009, Silva et al. 2009). Nenhum manejo especial era praticado na propriedade com a finalidade específica de otimizar a TIP. A baixa frequência de FTIP pode ser devida ao número muito baixo de trigêmeos nascidos e a características raciais. Deve-se salientar que os cordeiros estudados eram meio-sangue 
Texel e filhos de ovelhas frutos de cruzamento entre três raças com aptidão para a produção de carne. Como resultado, talvez em parte por causa da heterose, nasciam geralmente com bom peso e muito ativos e vigorosos. As ovelhas, mesmo as primíparas, apresentavam, de forma geral, muito boa habilidade materna.

As causas prováveis identificadas para os casos de FTIP foram mamite unilateral $(n=3)$, pouco interesse da ovelha pela cria ou rejeição $(n=4)$, letargia do cordeiro durante o primeiro dia de vida $(n=3)$, distocia $(n=1)$, necessidade de auxiliar o cordeiro a mamar o colostro $(n=3)$ e apatia da ovelha recém-parida $(n=3)$. Desses cordeiros, 12 eram únicos, 22 eram gêmeos e 2 eram trigêmeos; 25 eram machos e 11 eram fêmeas; e 25 pesavam $\geq 3 \mathrm{~kg}$ e 11 eram leves. As suas mães eram na maior parte primíparas $(n=13)$ e tinham ECC $2(n=19)$, sendo que somente três pariram muito magras (ECC 1). Comparados aos cordeiros com a TIP bem sucedida, os cordeiros com FTIP eram menos pesados $(4,104 \pm 0,963 \mathrm{~kg}$ contra $3,330 \pm 0,850 \mathrm{~kg} ; \mathrm{p}<0,05)$ e possuíam perímetro torácico menor $(36,920 \pm 3,410 \mathrm{~cm}$ contra $34,970 \pm 2,690 \mathrm{~cm} ; p<0,05)$.

O risco de FTIP foi maior nos cordeiros que nasceram com peso inferior a $3 \mathrm{~kg}$ e nos produtos de gestações gemelares (dois ou três fetos). O vigor exibido pelo cordeiro ao nascimento, contudo, não foi associado à ocorrência de FTIP (Quadro 3). Esses resultados são coerentes com os de outros estudos internacionais (Hunter et al. 1977, McGuire et al. 1983, Ahmad et al. 2000, Christley et al. 2003) e brasileiros (Nunes 2006, Flaiban et al. 2007, 2009) e seguramente caracterizam os principais fatores de risco para a FTIP em cordeiros. Como métodos capazes de reduzir a prevalência da FTIP, as práticas de vigilância mais intensificada e de auxílio para a mamada do colostro devem ser recomendadas nos casos de nascimento de gêmeos e/ou de cordeiros com baixo peso, especialmente se filhos de primíparas. É interessante observar que dentre os 22 gêmeos relacionados houve sete pares de irmãos, ou seja, os dois cordeiros nascidos apresentaram FTIP. Nos oito casos restantes o insucesso da TIP foi observado em somente um dos irmãos. Quando a ovelha é dócil, a interferência do homem auxiliando a ingestão do colostro talvez possa aumentar a probabilidade de sucesso em pelo menos um dos cordeiros gêmeos. Quando a

\section{Quadro 3. Associação entre fatores de risco e o sucesso (TIP) ou a falha (FTIP) na transferência de imunidade passiva em cordeiros mestiços de corte}

\begin{tabular}{llcccc}
\hline Fator & & TIP $(\%)$ & FTIP $(\%)$ & Total & $p$ \\
\hline Peso ao & $\geq 3 \mathrm{~kg}$ & $231(90,2)$ & $25(9,7)$ & 256 & $<0,001$ \\
nascimento & $<3 \mathrm{~kg}$ & $23(67,6)$ & $11(32,4)$ & 34 & \\
№ de fetos & Únicos & $139(92,0)$ & $12(8,0)$ & 151 & 0,026 \\
& Gêmeos* & $115(82,7)$ & $24(17,3)$ & 139 & \\
Vigor ao & Boa vitalidade & $242(88,0)$ & $33(12,0)$ & 275 & 0,608 \\
nascimento & Letárgico & $12(80,0)$ & $3(20,0)$ & 15 & \\
Morte até & Sobreviventes & $232(90,3)$ & $25(9,7)$ & 257 & $<0,001$ \\
60 dias & Mortos & $22(66,7)$ & $11(33,3)$ & 33 &
\end{tabular}

\footnotetext{
* Incluídos também os trigêmeos.
}

ovelha é indócil, por outro lado, essa interferência pode causar efeito indesejável aumentando a chance de rejeição de ambos os cordeiros.

A taxa de mortalidade global na população estudada até os 60 dias de vida foi de $11,3 \%(n=33)$. $E$, em coerência com outros relatos (Sawyer et al. 1977, Vihan 1988, Bekele et al. 1992, Nunes 2006), a associação entre a FTIP e a morte de cordeiros foi altamente significativa (Quadro 3). Nos cordeiros com FTIP a mortalidade foi de $30,5 \%$ contra $8,6 \%$ nos demais. Ou seja, cordeiros com FTIP apresentaram risco 3,5 vezes maior de morrerem. Quase todas as mortes (9/11) dos cordeiros com FTIP ocorreram no primeiro mês de vida, especialmente na primeira semana (6/11). Nos cordeiros com a TIP bem sucedida, por outro lado, as mortes foram bem distribuídas entre o primeiro mês (9/22) e o segundo mês de vida (13/22), sendo que 8 ocorreram após 45 dias de idade. Embora as causas específicas das mortes não tenham sido investigadas criteriosamente nesse trabalho, é coerente suspeitar que as causas infecciosas, as quais predominam no primeiro mês de vida (Sawyer et al. 1977, Radostits et al. 1994, Kahn et al. 2006, Nunes 2006), foram mais importantes nos cordeiros com FTIP. A sobrevivência relativamente alta nos cordeiros com FTIP deve-se ao padrão de manejo extensivo e às práticas de higiene das instalações adotados na propriedade, o que reduz a chance e a magnitude de exposição dos cordeiros neonatos aos agentes patogênicos.

Considerando os valores obtidos em todos os 290 cordeiros, a concentração de gamaglobulinas se correlacionou $(p<0,001)$ com as concentrações de proteína total determinada por refratometria $(r=0,816)$ e pelo método colorimétrico $(r=0,880)$, de globulinas $(r=0,990)$ e de lgG $(r=0,796)$ e com a atividade da GGT $(r=0,575)$. A concentração de $\lg G$ se correlacionou $(p<0,001)$ com as concentrações de proteína total determinada por refratometria $(r=0,810)$ e pelo método colorimétrico $(r=0,638)$, de globulinas $(r=0,782)$ e com a atividade da GGT $(r=0,510)$. Isso prova que a determinação da proteína total por refratometria pode ser empregada com confiabilidade para identificar os indivíduos portadores de FTIP. O método é barato e simples, e pode ser realizado no campo com resultados rápidos, bastando aguardar a retração do coágulo para a obtenção de um pequeno volume de soro. Com base nos resultados obtidos e nos critérios apontados por Sawyer et al. (1977), seria possível considerar o valor de 5,1 a 6,0g/ dL de proteína total como indicativo de falha parcial da transferência de imunidade passiva, e o valor inferior ou igual a $5,0 \mathrm{~g} / \mathrm{dL}$ como indicativo de falha total da transferência de imunidade passiva nos cordeiros.

Em conclusão, pode-se admitir que, nos cordeiros mestiços de raças de corte manejados extensivamente sob condições de clima tropical, a TIP não é influenciada pelo sexo do cordeiro, pelo ECC da ovelha ao parto e pelo número de partos da ovelha. A FTIP apresenta baixa prevalência e forte associação com a mortalidade neonatal, sendo mais provável nos gêmeos e/ou nos cordeiros nascidos 
com baixo peso (inferior a $3 \mathrm{~kg}$ ). A vigilância e interferência do homem devem ser intensificadas nesses casos.

Agradecimentos.- Ao Prof. Dr. Francisco Leydson Formiga Feitosa, do Departamento de Clínica, Cirurgia e Reprodução Animal, FOA, Unesp, Campus de Araçatuba, pela cessão dos padrões de IgG ovina do kit de imunodifusão radial.

\section{REFERÊNCIAS}

Ahmad R., Khan A., Javed M.T. \& Hussain I. 2000. The level of immunoglobulins in relation to neonatal lamb mortality in Pak-Karakul sheep. Vet. Arh. 70(3):129-139.

Al-Sabbagh T.A., Swanson L.V. \& Thompson J.M. 1995. The effect of ewe body condition at lambing on colostral immunoglobulin $G$ concentration and lamb performance. J. Anim. Sci. 73(10):2860-2864.

Bekele T., Otesile E.B. \& Kasali O.B. 1992. Influence of passively acquired colostral immunity on neonatal lamb mortality in Ethiopian highland sheep. Small Rumin. Res. 9(3):209-215.

Campos A.G.S.S., Afonso J.A.B., Santos R.A. \& Mendonça C.L. 2009. Uso do propilenoglicol, cobalto e vitamina $B_{12}$ em ovelhas e seus reflexos sobre o perfil eletroforético das proteínas séricas dos borregos. Cienc. Anim. Bras. 1(Supl.):140-145.

Christley R.M., Morgan K.L., Parkin T.D.H. \& French N.P. 2003. Factors related to the risk of neonatal mortality, birth-weight and serum immunoglobulin concentration in lambs in the UK. Prev. Vet. Med. 57(4):209-226.

Ciupercescu D.D. 1977. Dynamics of serum immunoglobulin concentrations in sheep during pregnancy and lactation. Res. Vet. Sci. 22(1): 23-27.

Curi P.R. 1998. Delineamentos experimentais: análise de variância, p.198-211. In: Ibid. (Ed.), Metodologia e Análise da Pesquisa em Ciência Biológica. $2^{\mathrm{a}}$ ed. Tipomic, Botucatu.

Flaiban K.K.M.C., Costa M.C., Balarin M.R.S., Ribeiro E.L.A., Mori R.M. \& Lisbôa J.A.N. 2007. Transferência de imunidade passiva em cordeiros cujas mães sofreram restrição protéica no terço final de gestação. Arch. Vet. Sci. 12(Supl.):187-188.

Flaiban K.K.M.C., Balarin M.R.S., Ribeiro E.L.A., Castro F.A.B., Mori R.M. \& Lisbôa J.A.N. 2009. Transferência de imunidade passiva em cordeiros cujas mães receberam dietas com diferentes níveis de energia ou proteína no terço final de gestação. Ciênc. Anim. Bras. 1(Supl.):181-185.

Gilbert R.P., Gaskins C.T., Hillers J.K., Parker C.F. \& McGuire T.C. 1988. Genetic and enviromental factors affeting immunoglobulin G1 concentrations in ewe colostrum and lamb serum. J. Anim. Sci. 66(4):855-863.

Halliday R. 1976. Variations in immunoglobulin concentrations in Finnish x Dorset Horn lambs. Res. Vet. Sci. 21(3):331-334.

Halliday R. 1978. Immunity and health in young lambs. Vet. Rec. 103(22): 489-492.

Hashemi M., Zamiri M.J. \& Safdarian M. 2008. Effects of nutritional level during late pregnancy on colostral production and blood immunoglobulin levels of Karakul ewes and their lambs. Small Rumin. Res. 75(2):204-209.

Hough R.L., McCarthy F.D., Thatcher C.D., Kent H.D. \& Eversole D.E. 1990. Influence of glucocorticoid on macromolecular absorption and passive immunity in neonatal lambs. J. Anim. Sci. 68(8):2459-2464.

Hunter A.G., Reneu J.K. \& Williams J.B. 1977. Factors affecting IgG concentration in day-old lambs. J. Am. Vet. Med. Assoc. 45(5):1146-1151.

Kaneko J.J. 1997. Serum proteins and the dysproteinemia, p.117-138. In: Kaneko J.J., Harvey J.W. \& Bruss M.L. (Eds), Clinical Biochemistry of Animals. $5^{\text {th }}$ ed. Academic Press, San Diego.
Keay G. \& Doxey D.L. 1984. Serum protein values from healthy ewes and lambs of various ages determined by agarose gel electrophoresis. Brit. Vet. J. 140(1):85-88.

Khan A., Sultan M.A., Jalvi M.A. \& Hussain I. 2006. Risk factors of lamb mortality in Pakistan. Anim. Res. 55(4):301-311.

Kremers B., Briere R.O. \& Batsakis J.G. 1967. Reflectance densitometry of cellulose acetate protein eletrophoresis. Am. J. Med. Technol. 33(1): 28-34.

McGuire T.C., Regnier J., Kellom T. \& Gates N. 1983. Failure in passive transfer of immunoglobulin $\mathrm{G} 1$ to lambs: measurement of immunoglobulin G1 in ewe colostrums. Am. J. Vet. Res. 44(6):10641067.

Mellor D.J. \& Murray L. 1985. Effects of maternal nutrition on udder development during late pregnancy and on colostrums production in Scottish Blackface ewes with twin lambs. Res.Vet. Sci. 39(2):230234.

Mellor D.J. \& Murray L. 1986. Making the most of colostrum at lambing. Vet. Rec. 118(13):351-353.

Nunes A.B.V. 2006. Estudo da transmissão da imunidade passiva e da mortalidade em cordeiros mestiços de Santa Inês, na região Norte de Minas Gerais. Dissertação de Mestrado em Medicina Veterinária, Escola de Veterinária, Universidade Federal de Minas Gerais, Belo Horizonte, MG. 83p.

Pfeiffer N.E., McGuire T.C., Bendel R.B. \& Weikel J.M. 1977. Quantitation of bovine immunoglobulins: comparison of single radial immunodiffusion, zinc sulfate turbidity, serum electrophoresis, and refractometer methods. Am. J. Vet. Res. 38(5):693-698.

Radostits O.M., Leslie K.E. \& Fetrow J. 1994. Health and production management for sheep, p.527-606. In: Ibid. (Eds), Herd Health: Food animal production medicine. W.B. Saunders, Philadelphia.

Rankins D.L., Ruffin D.C. \& Pugh D.G. 2005. Alimentação e nutrição, p.21-66. In: Pugh D.G. (Ed.), Clínica de Ovinos e Caprinos. Roca, São Paulo.

Sawyer M., Willadsen C.H., Osburn B.I. \& McGuire T.C. 1977. Passive transfer of colostral immunoglobulins from ewe to lamb and its influence on neonatal lamb mortality. J. Am. Vet. Med. Assoc. 171(12):12551259.

Silva D.F.M., Costa J.N., Araújo A.L., Carvalho S., Peixoto A.P.C., Alves L.O. \& Ferreira M.M. 2009. Falha da transferência da imunidade passiva em cordeiros mestiços (Santa Inês x Dorper): efeito no proteinograma e taxa de mortalidade do nascimento até o desmame. Ciênc. Anim. Bras. 1(Supl.):158-163.

Silva D.F.M., Costa J.N., Araújo A.L., Costa Neto A.O. \& Almeida M.A. 2007. Proteinograma sérico de cordeiros mestiços (Santa Inês $x$ Dorper) do nascimento até os 90 dias de idade: efeito do desenvolvimento etário e do monitoramento da ingestão do colostro. Arch. Vet. Sci. 12(Supl.):86-87.

Swanson T.J., Hammer C.J., Luther J.S. Carlson D.B., Taylor J.B., Redmer D.A., Neville T.L., Reed J.J., Reynolds L.P., Caton J.S. \& Vonnahme K.A. 2008. Effects of gestational plane of nutrition and selenium supplementation on mammary development and colostrums quality in pregnant ewe lambs. J. Anim. Sci. 86(9):2415-2423.

Szasz G. 1969. A kinetic photometric method for serum gammaglutamyl transpeptidase. Clin. Chem. 15(2):124-36.

Tizard I.R. 2002. Imunidade no feto e no recém-nascido, p.233-246. In: Ibid. (Ed.), Imunologia Veterinária: Uma introdução. 6ª ed. Roca, São Paulo.

Vihan V.S. 1988. Immunoglobulin levels and their effect on neonatal survival in sheep and goats. Small Rumin. Res. 1(2):135-144.

Waelchli R.O., Müller C., Hässig M. \& Rüsch P. 1994. Immunoglobulin concentrations in colostrums and serum of lambs of dairy sheep breeds. Vet. Rec.135(1):16-17. 